\title{
Nível de autocompaixão e de afetos positivos e negativos em mães de filhos atendidos em um ambulatório psicológico
}

The level of self-compassion and positive and negative affections in mothers of children attended at a psychological clinic

\author{
Izabel Stockey Chinchilha ${ }^{1}$ \\ Maikon de Sousa Michels ${ }^{2}$
}

\begin{abstract}
RESUMO
Este estudo teve como objetivo investigar o grau de autocompaixão e de afetos negativos/positivos em mães de filhos em processo psicoterapêutico. Os resultados indicaram escores altos de afetos negativos e escores baixos de afetos positivos e de autocompaixão. Foi identificado histórico de violência, depressão, ansiedade e culpa.
\end{abstract}

PALAVRAS-CHAVE: Autocompaixão. Afetos Positivos e Negativos. Mulheres. Maternidade.

\begin{abstract}
This study has the main objective to investigate the degree of self-compassion and negative/positive affections in mothers of children in the psychotherapeutic process. The results found indicated high scores of negative affections and low scores of positive affections and self-compassion. Also, a history of violence, depression, anxiety, and guilt has identified.
\end{abstract}

KEYWORDS: Self-compassion. Positive and Negative Affections. Women. Maternity.

$$
* * *
$$

Introdução

Os dados do Instituto Brasileiro de Pesquisa e Estatística de 2014, indicam que houve uma prevalência maior de depressão em mulheres (10,9\%) do que em homens (3,9\%) (SOUZA e HUTZ, 2016). Acredita-se que esses níveis de depressão maiores em mulheres podem apresentar uma relação com a autocompaixão. Como aponta Neff (2003), as mulheres apresentaram menor índice ou nível de 
autocompaixão quando comparadas aos homens. A autocompaixão fornece uma capacidade de sermos gentis com nós mesmos em momentos de sofrimento ou de felicidade. É uma forma do sujeito ser compreensivo e menos crítico consigo, além de entender que os problemas são dignos de serem trabalhados (NEFF, 2017).

A saúde mental de homens e mulheres é importante para o entendimento deste estudo. Como indica Apóstolo (2007 apud APÓSTOLO et al., 2008), mulheres já apresentam maior susceptibilidade em relação ao homem de desenvolver perturbações afectivo-emocionais e também desenvolver transtornos de depressão, ansiedade e o stress.

Conforme Apóstolo et al. (2008, p. 47), as mulheres apresentam níveis médios mais elevados de ansiedade e de depressão relativamente aos homens. Entender como mulheres, que ainda desempenham papel de mães, devem ter sua autocompaixão afetada pela pressão social que sofrem é uma questão que sustenta este artigo. De acordo com Sanchez (2014), a relação construída entre uma mãe e seu filho influencia o desenvolvimento do comportamento e características de temperamento apresentados pela criança. Desta forma, uma mãe com uma boa saúde mental e bem-estar irá refletir em seu filho. Logo, a investigação de quais características cognitivas e afetivas as mães que têm filhos atendidos em ambulatório psicológico são de significativa relevância.

De acordo com Gilbert (2014), a Terapia Focada na Compaixão (TFC) sugere que cada pessoa possa ser mais compassiva consigo mesma e com os outros, sendo mais compreensivo e empático. Como indica Neff (2017), quando não conseguimos atingir as expectativas que colocamos sobre nós mesmos, começamos a duvidar de nossas capacidades e potenciais, ficamos frustrados e perdemos a esperança. Dessa forma, acabamos desencadeando comportamentos e cognições autodestrutivas e autocriticismo, desenvolvendo problemas de saúde mental (GILBERT, 2014). A autocompaixão em mães ainda pode estar relacionada com os afetos positivos e negativos que elas desempenham ao longo da vida, pois segundo Hutz et al. (2014), estes afetos em conjunto com o nível de satisfação com a vida compõe o bem-estar subjetivo de cada indivíduo. Conforme Diener (1984 apud WOYCIEKOSKI, NATIVIDADE e HUTZ, 2014), o bem estar subjetivo é um fenômeno que inclui respostas emocionais e julgamentos globais sobre a satisfação com a vida. De 
acordo com Woyciekoski, Natividade e Hutz (2014, p. 401)

As respostas emocionais correspondem a julgamentos de emoções e humores, juntos denominados afetos, feitos pelos próprios indivíduos sobre situações atuais de suas vidas. A satisfação com a vida visa à avaliação de crenças e pensamentos relacionados às suas vidas de maneira geral.

Conforme Diener, Oishi e Lucas (2009), os afetos positivos e negativos compõe uma tríade do bem-estar subjetivo (BES), no qual os afetos correspondem à dimensão emocional do BES. Logo, o nível de afetos positivos e negativos que uma mãe vive acaba influenciando em seu bem-estar e autocompaixão, o que consequentemente influencia na sua relação com seu (s) filho (s), parceiro, familiares e conhecidos. A autocompaixão está ligada às emoções que temos no dia a dia, no qual em níveis altos corresponde a maiores níveis de afetos positivos e em níveis baixos pode indicar maiores níveis de afetos negativos. Desta forma, foi determinado que para este estudo seria avaliado os níveis de afetos positivos e negativos em relação ao nível de autocompaixão.

Logo, o objetivo deste trabalho é investigar o nível de autocompaixão e de afetos positivos e negativos em mães que têm seus filhos atendidos em ambulatório psicológico, através da aplicação das escalas e entrevista.

A autocompaixão implica no lado cognitivo do indivíduo, sendo bom e compreensivo consigo, observando os pensamentos e sentimentos que podem surgir de acordo com suas vivências (SOUZA e HUTZ, 2016). Desta forma, a aplicação de questionários para avaliar os aspectos emocionais e cognitivos pode tornar os resultados mais confiáveis.

A próxima sessão do artigo corresponde a fundamentação teórica. Em seguida, será explicado a metodologia. Logo após, os resultados serão mostrados e discutidos e por fim, as considerações finais deste manuscrito.

Fundamentação teórica

A compaixão é uma palavra de raízes budistas e cristãs, no qual remete a consciência acerca do sofrimento do outro, sendo compreensível e sensível como 
uma forma de encontrar alívio para o outro (SIMÕES, 2012). Conforme Simões (2012), a compaixão dá um sentido de interdependência e interconectividade para o sujeito, assim como auxilia na coexistência e partilha da dor. Neste trabalho, os dois principais autores utilizados para o embasamento teórico e discussões sobre (Auto) Compaixão são Kristin Neff e Paul Gilbert, esse último o fundador da Terapia Focada na Compaixão. Ambos os autores são reconhecidamente referências internacionais sobre o estudo da (Auto) Compaixão.

Neff (2017) descreve a compaixão em duas situações diferentes, a compaixão por outros e a compaixão por nós mesmos (autocompaixão). A compaixão pelos outros compõem uma visão mais abrangente sobre o sofrimento, sendo que amplia o olhar focando mais no sofrimento do outro. Neff (2017) coloca que esta compaixão acaba por desenvolver uma condição humana compartilhada, imperfeita e frágil. Essa autora afirma que a compaixão por nós mesmos possui a mesma qualidade, mas com um olhar voltado para si, reconhecendo o próprio sofrimento.

Ao mesmo tempo, a autocompaixão promove estados mentais positivos, como a felicidade e o otimismo. Cultivar a qualidade da autocompaixão nos permite florescer e apreciar a beleza e a riqueza da vida, mesmo em tempos difíceis. Quando acalmamos nossas mentes agitadas com a autocompaixão, somos mais capazes de perceber o que está certo e o que está errado. Podemos nos orientar na direção do que nos dá alegria (NEFF, 2017, p. 21).

Neff (2017) afirma que a autoestima e autocompaixão são dois lados da mesma moeda, sendo que autoestima está focada em nossa satisfação, enquanto a autocompaixão está focada em nosso sofrimento. Ou seja, nem sempre o indivíduo se encontra satisfeito com ele mesmo, no qual acaba desenvolvendo uma baixaautoestima. Já na autocompaixão, mesmo estando em sofrimento, o indivíduo é capaz de fornecer conforto para si, aceitando os erros ao invés de se autocriticar (NEFF, 2017).

Conforme a Terapia Focada na Compaixão (TFC), existem dois tipos de compaixão: pode ser a relação de uma pessoa para os outros e também a compaixão consigo mesmo. A TFC tem como base a evolução de competências motivacionais, emocionais, comportamentais e cognitivas que nos permite notar, se engajar e 
trabalhar para endereçar a angústia e as necessidades do self e de outros. Desta forma, é sustentada a busca e a resposta ao cuidado, à ajuda, ao compartilhamento e à gentileza (GILBERT, 2014).

Conforme Gilbert (2014), nós não escolhemos nossas características. Nosso self é resultado de uma construção genética e social. Nós somos moldados pela sociedade e pelo ambiente em que crescemos. Logo, se uma pessoa cresce em um ambiente hostil e violento, ela provavelmente vai desenvolver uma personalidade mais agressiva e menos empática. Desta forma, o trabalho da compaixão é compreender este lado do ser humano.

De acordo com Gilbert (2014), em estudos realizados entre mulheres, foi encontrada uma correlação entre o aumento da idade com o aumento na autoestima e autocompaixão. Também foi identificado uma relação entre índices de bem-estar em mulheres sem filhos por opção do que mulheres com filhos. Estas mulheres sem filhos por opção apresentaram maior bem-estar psicológico e maior senso de autonomia do que as mulheres que não podem ter filhos, conforme Jeffries e Konnert (2002).

Ainda para Gilbert (2014, p. 96), a relação entre ter filhos e ter maior autocompaixão pode ser sustentada pelas habilidades maternas ou estilos parentais: "a autocompaixão está circundada por desafios relacionados às dificuldades, erros, inadequações e fracassos percebidos com relação a criar e cuidar dos filhos".

Gilbert (1992 apud GILBERT, 2014) sustenta essa vivência citada anteriormente, visto que a comparação social é um dispositivo no processamento de relações baseadas em domínios de inferior-superior. E o mesmo é relacionado ao orgulho-vergonha, assertividade e auto criticismo encontrado em comportamentos dos seres humanos.

Conforme exposto anteriormente pelos dois principais autores utilizados nesse estudo, Kristin Neff e Paul Gilbert, a (Auto) compaixão está relacionada com outras emoções. Níveis altos de Compaixão, por exemplo, auxiliam o indivíduo a lidar melhor com o sofrimento inerente ao ser humano, ao passo que níveis baixos de Compaixão estão relacionados à vergonha e autocriticismo. Sendo assim, também se optou por avaliar os afetos positivos e negativos para verificar se há 
relação entre os níveis de afetos positivos e negativos e Compaixão.

Os afetos negativos e positivos correspondem a dimensão emocional do BemEstar Subjetivo. Além disso, o bem-estar subjetivo possui a satisfação de vida como dimensão cognitiva. Logo, conforme Diener (1999 apud WOYCIEKOSKI, STENERT e HUTZ, 2012, p. 281) "a satisfação de vida é uma avaliação cognitiva positiva da vida como um todo; afeto positivo expressa a frequência de emoções positivas experimentadas pelo sujeito, e afeto negativo a frequência de emoções negativas".

Desta forma, a relação entre mãe e filho está muito ligada à saúde e desenvolvimento da criança. Conforme Sanchez (2014, p. 103), o recém-nascido não só precisa de uma boa saúde física, mas também a interação adequada com a sua mãe: "os cuidados precoces com a formação cognitiva da criança são medidas preventivas aos riscos posteriores à sua saúde mental”. Logo, a modelagem do comportamento futuro e características comportamentais da criança é desde cedo estabelecida na relação de mãe e filho (SANCHEZ, 2014). Tal relação afirma a importância desta mãe ter uma saúde mental e ser reconhecida em suas dificuldades e sofrimento. Como propõe Neff (2017), assumir a compaixão torna mais fácil para uma mãe ou pai admitir que existem imperfeições como pais e é mais fácil para pedir desculpa por um comportamento errado. Neff (2017) ainda inclui que esta autocompaixão não só ajuda os filhos a se sentirem amados e cuidados, como também permite o reconhecimento das dificuldades do papel de ser mãe e pai e como seres humanos.

Conforme Neff (2017, p. 207), "talvez você seja cuidadoso e dê apoio e suporte para seus filhos quando eles dão um passo em falso. Mas se você é cruel consigo sempre que fracassa, vai enviar a mensagem errada à sua família”. Portanto, reconhecer as limitações e demonstrar isto para o outro é uma forma de modelar a autocompaixão, para que os filhos consigam desenvolver essa habilidade.

Metodologia

$\mathrm{O}$ presente artigo teve a metodologia baseada na abordagem quanti e qualitativa. Conforme Godoy (1995), a pesquisa qualitativa tem como principal 
objetivo estudar e analisar o mundo empírico, sendo uma pesquisa descritiva, no qual o fenômeno estudado deve ser compreendido no contexto do qual faz parte. De acordo com Gerhardt e Silveira (2009), o método qualitativo explica o porquê das coisas, sem enfatizar valores e números, os dados analisados são não-métricos. É importante trabalhar com a realidade que não é quantificada, focando em compreender e explicar as relações sociais (GERHARDT e SILVEIRA, 2009). Já a pesquisa quantitativa, conforme Gerhardt e Silveira (2009, p. 33), "tem suas raízes no pensamento positivista lógico, tende a enfatizar o raciocínio dedutivo, as regras da lógica e os atributos mensuráveis da experiência humana". É importante ressaltar que quando usada a abordagem quantitativa, existe uma vantagem no que se diz sobre os resultados. A pesquisa quantitativa é capaz de gerar resultados generalizáveis, indicando parâmetros entre os resultados, auxiliando em uma visão geral deles (GÜNTHER, 2006).

Neste artigo foram utilizadas duas escalas: PANAS (Escala de Afetos Positivos e Afetos Negativos) e a "Escala de Autocompaixão: como eu realmente lido comigo em momentos difíceis". Hutz et al. (2014) descreve que a escala de afetos positivos e afetos negativos (PANAS) tem como objetivo mensurar a frequência e intensidade no qual são vivenciados esses afetos, o qual irá refletir nos níveis de bem-estar e felicidade do entrevistado. Essa escala é composta de 10 afetos positivos e 10 afetos negativos, no qual o sujeito deve classificar de 1 a 5 cada item, sendo 1 "nem um pouco" e 5 "extremamente". A escala de autocompaixão, conforme Hutz (2016), tem como objetivo avaliar como o sujeito lida consigo em momentos difíceis e de sofrimento. A escala de compaixão possui 26 afirmações no qual o respondente também deve classificar de 1 a 5, entretanto 1 sendo "quase nunca" e 5 sendo "quase sempre". A metodologia também envolveu uma entrevista semiestruturada composta por 5 perguntas abertas, no qual foram gravadas e posteriormente transcritas pelo pesquisador. Conforme Boni e Quaresma (2005), a entrevista semiestruturada é a combinação de perguntas abertas e fechadas, no qual o pesquisador e o entrevistado podem discorrer sobre o tema.

A partir da coleta de dados foi realizada uma leitura flutuante das entrevistas. De acordo com Cavalcante, Calixto e Pinheiro (2014), esta leitura 
compõe uma pré-análise das entrevistas, no qual são formuladas e reformuladas hipóteses e pressupostos. Logo, existe um contato direto e intenso com o material coletado, no qual foram formuladas as categorias de análise. Foram construídas três categorias de análise, sendo estas: violência (física, psicológica e sexual), depressão e ansiedade e autocrítica e culpa.

A pesquisa foi realizada com mulheres que também desempenham papel de mãe, no qual possuem pelo menos um (a) filho (a) que faz atendimento psicológico no Serviço de Psicologia da Univille (Spsi). Essa instituição proporciona atendimento psicológico gratuito para pessoas da comunidade. No Serviço de Psicologia da Univille (Spsi), os atendimentos são feitos por acadêmicos do quinto ano de psicologia da Univille e supervisionados por um professor psicólogo. O processo de coleta de dados para a pesquisa foi feito no Spsi. Foram avaliadas 10 mulheres ao todo, no qual a aplicação de escalas e as entrevistas foram feitas enquanto as mães aguardavam o atendimento de seu filho (a).

Antes de iniciarem as entrevistas, o projeto de pesquisa foi submetido à plataforma Brasil e aprovado pelo comitê de pesquisa sob o número de aprovação: 89912518.1.0000.5366. Para que a entrevista pudesse ser realizada, cada participante teve que assinar o Termo de Consentimento Livre e Esclarecido.

Análise e discussão dos resultados

Resultados quantitativos

Conforme explicado a respeito da metodologia, foram aplicadas as escalas: Escala de Afetos Positivos e Afetos Negativos e a Escala de Autocompaixão: como eu realmente lido comigo em momentos difíceis. Os resultados podem ser visualizados na Tabela 1. Os percentis foram obtidos com base nos estudos de Souza e Hutz (2016). Os escores brutos são convertidos em percentis nas tabelas normativas de cada uma das escalas aplicadas.

Tabela 1: Percentil de afetos positivos, negativos e autocompaixão das participantes

PARTICIPANTES 


\begin{tabular}{cccc}
\hline & & NEGATIVOS & \\
\hline P1 & 25 & 95 & 40 \\
\hline P2 & 25 & 95 & 15 \\
\hline P3 & 5 & 95 & 10 \\
\hline P4 & 25 & 50 & 45 \\
\hline P5 & 5 & 75 & 15 \\
\hline P6 & 90 & 50 & 45 \\
\hline P7 & 5 & 95 & 25 \\
\hline P8 & 50 & 75 & 30 \\
\hline P9 & 5 & 75 & 40 \\
\hline P10 & 50 & 50 & 40 \\
\hline Média & 10 & 75 & \\
\hline
\end{tabular}

Fonte: Primária (2019).

As participantes em média se encontram no percentil 10 de afetos positivos, ou seja, possuem escores maiores que $10 \%$ da amostra apresentada na escala padrão (HUTZ et al., 2014). Para os afetos negativos as mesmas se encontram no percentil 75, ou seja, possuem escores maiores que 75\% da escala padrão. Já para a autocompaixão, as participantes se encontram no percentil 40, ou seja, possuem escores maiores que $40 \%$ da escala normalizada.

Isso demonstra que as mulheres avaliadas nesta pesquisa possuem, em média, menores escores de afetos positivos, maiores escores de afetos negativos e menores escores de autocompaixão se comparados com as tabelas normativas da população brasileira.

A partir da Tabela 1, foi possível identificar que 7 entre 10 participantes da amostra desta pesquisa estão entre os percentis 5 e 25 para afetos positivos. Ou seja, estão em percentis abaixo de 30, o que significa que possuem escores muito baixos comparado com a média da população (Hutz, 2016). Para os afetos negativos, 7 entre 10 participantes da amostra da pesquisa estão entre percentis de afetos negativos entre 75 e 95, o que significa que possuem escores altos se comparados com a média da população (Hutz, 2016). Portanto, os resultados 
indicam que a amostra tem um número alto de participantes com afetos positivos com escores baixos e afetos negativos com escores altos.

Conforme a Tabela 1 foi gerado o Gráfico 1, que é um comparativo entre os resultados da aplicação das escalas com todas as participantes. O critério para comparação usou como base os percentis em que cada participante se encontra, assim os resultados podem ser visualizados de forma mais clara.

Gráfico 1: Comparação de percentis de afetos negativos, positivos e autocompaixão por participante.

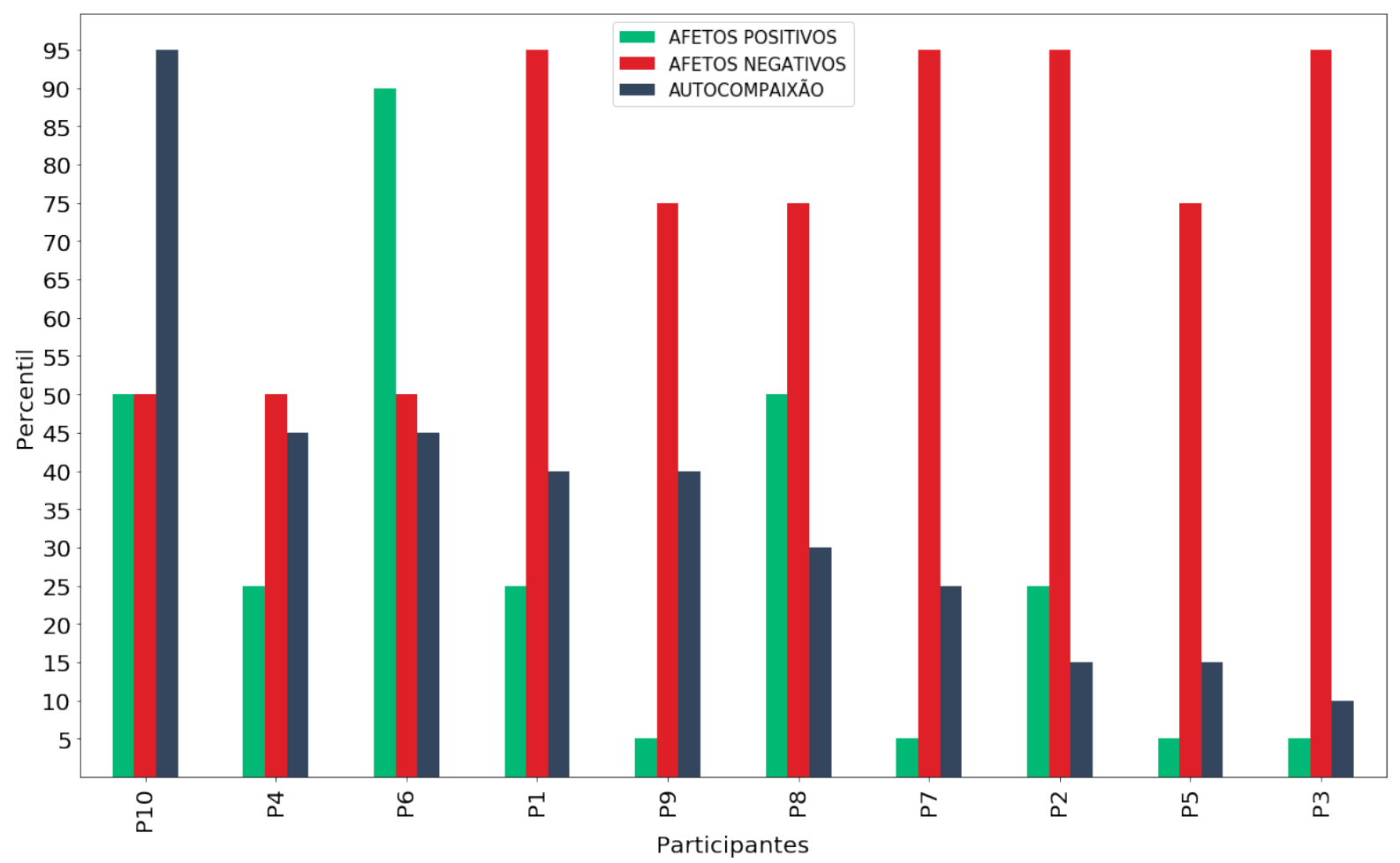

Fonte: Primária (2019).

Com base no Gráfico 1, observa-se que na maioria das participantes, níveis altos de afetos negativos estão associados com níveis mais baixos de autocompaixão. Já a participante que está em percentis médios de afetos positivos e negativos foi a que apresentou melhor nível de autocompaixão. Ela está junto dos $5 \%$ de pessoas com maiores escores de autocompaixão segundo a "Escala de Autocompaixão: como eu realmente lido comigo em momentos difíceis" (NEFF, 2017). Esta mesma participante também relatou que fez acompanhamento terapêutico, o que pode ter contribuído para seu desempenho. Também podemos ver que as três participantes com melhores escores de autocompaixão, estão no 
percentil 50 de afetos negativos e estão em níveis percentis variados de afetos positivos.

As participantes denominadas $\mathrm{P} 4$ e P6, estão no mesmo percentil de afetos negativos e autocompaixão. Porém estão em percentis de afetos positivos bastante distintos, 25 e 90 respectivamente, o que pode indicar que existem outros fatores influenciando o nível de autocompaixão. P4 não relatou ter sofrido violência, como a P6 trouxe em sua fala, entretanto, P6 afirmou ter feito acompanhamento psicológico, tornando mais fácil para ela lidar com essas questões, podendo assim influenciar no escore de afetos positivos.

O menor nível de autocompaixão da amostra foi de percentil 10, ou seja, possui autocompaixão maior que apenas $10 \%$ das pessoas da escala de Hutz et al. (2014). Essa participante possui escores baixos de afetos positivos e altos de afetos negativos. Esta mesma participante se enquadra nas categorias de ter sofrido violência psicológica ${ }^{1}$, apresentou falas que remetem à depressão e ansiedade e também apresentou pensamentos autocríticos e de culpa. Estes fatores podem ter influenciado em seus escores.

A participante $\mathrm{P} 4$, no qual apresenta apenas pensamentos autocríticos e de culpa, obteve o nível de autocompaixão melhor que 50\% da amostra padronizada de Hutz et al. (2014). P3, P5 e P7 relataram que sofreram violência psicológica e estão no mesmo percentil (5) de afetos positivos, o que indica que as mesmas possuem um escore de afetos positivos maior do que apenas 5\% das participantes da amostra padronizada de Hutz et al. (2014).

A partir desta análise foi possível compreender que à medida que os níveis de autocompaixão diminuem, os níveis de afetos positivos variam, o que impossibilita dizer que possui uma correlação forte entre esses valores.

Já para os níveis de afetos negativos pode-se dizer que existe uma correlação maior, pois os menores escores de autocompaixão ocorreram para as participantes com altos escores de afetos negativos. As participantes com os menores escores de autocompaixão se encontram nos percentis entre 75 e 95 de afetos negativos, ou seja, possuem escores negativos ao menos $75 \%$ superiores aos da amostra padronizada de Hutz et al. (2014). Para indicar a variação nos dados coletados,

\footnotetext{
${ }^{1}$ As categorias de análise serão discutidas posteriormente na parte qualitativa dos resultados.
} 
existem quatro participantes que se encontram nos mesmos percentis para afetos positivos e negativos, porém estão em percentis diferentes de autocompaixão.

As participantes P1 e P2, estão nos mesmos percentis de afetos positivos e negativos, entretanto estão em percentis diferentes de autocompaixão. Essa diferença pode se dar devido às vivências diferentes entre as participantes. No caso de P1, ela está dentro das categorias de violência, tendo apresentado falas de depressão e ansiedade e pensamentos autocríticos e de culpa. Já a participante P2 está apenas nas categorias de ter apresentado falas de depressão e ansiedade e pensamentos autocríticos e de culpa, porém P2 tem um escore de autocompaixão menor que $\mathrm{P} 1$.

Entretanto, as participantes P5 e P9 apresentam a mesma situação de P1 e P2 quanto aos percentis, mas se enquadram em todas as categorias. A P5 apresentou falas sobre violência física e psicológica, depressão e ansiedade e apresentou pensamentos de autocriticismo e culpa. A P9 apresentou as mesmas categorias, porém não apresentou falas de violência psicológica. Isto pode ter corroborado para que seu escore de autocompaixão tenha sido maior que P5.

De acordo com Gilbert (2014), a teoria da Terapia Focada na Compaixão, possui como um importante pilar a relação entre os três sistemas de regulação do afeto: sistema de ameaça e proteção, sistema de busca de recompensa e o sistema de contentamento (soothing). Estes três sistemas funcionam regulando um ao outro, no qual são focadas três funções das emoções. Estas funções são:

(1) alertar para ameaças e ativar estratégias defensivas; (2) fornecer informação sobre a disponibilidade de recursos e recompensas e ativar estratégias de busca-engajamento; e (3) fornecer informação sobre segurança, permitir o repouso e a relativa inação na forma de contentamento e abertura (openness) (GILBERT, 2014, p.14).

Conforme os dados encontrados, é possível identificar a relação dos três sistemas de regulação do afeto com os resultados obtidos nas escalas e entrevista. Estes três sistemas são a forma como o sujeito tende a lidar com certas situações, buscando atender as necessidades de cada indivíduo. O sistema de ameaça e proteção possui emoções defensivas, por exemplo, raiva e ansiedade, e 
comportamentos (luta, fuga, congelamento e submissão) que visam proteção e segurança focada na ameaça (GILBERT e TIRCH, 2009). Em relação a este sistema, Gilbert e Tirch (2009, web) descrevem: "uma vez ativado, ele cria vários padrões fisiológicos no corpo, associados a experiências sentidas que direcionam o pensamento e as tendências das ações". Logo, esses sentimentos são capazes de atravessar os corpos, deixando o sistema em alerta e fazendo com que as ações no momento visam se proteger da ameaça (GILBERT, 2010).

Conforme Gilbert e Tirch (2009) o segundo sistema de regulação do afeto é o sistema de busca por recompensas (drive), no qual orienta o indivíduo para coisas recompensadoras, como comida, sexo, dinheiro e status. Desta forma, o sistema drive está ligado a afetos de excitação, consequentemente ligado a afetos positivos, quando em níveis saudáveis e funcionais.

Já no sistema de contentamento (soothing), seu objetivo é permitir que o indivíduo fique calmo quando não existe uma ameaça, sendo que este sistema está associado e um estado de bem-estar pacífico (soothing). Este mesmo sistema, pode vir a ser ativado por estímulos sociais de afeição, amor e cuidado (GILBERT e TIRCH, 2009). Desta forma, a partir da (auto) compaixão este sistema é ativado, com níveis mais baixos de compaixão o sistema acaba sendo pouco ativado.

Logo, como a maior parte das participantes possui afetos positivos mais baixos e afetos negativos mais altos, é possível compreender que provavelmente o sistema de ameaça e proteção está mais ativo do que o sistema de busca por recompensas e o sistema de contentamento. Gilbert (2014) propõe que ao estar com o sistema de ameaça e proteção muito ativo, pode causar certos danos a esses indivíduos, no qual é criado um "viés de negatividade", ou seja, a atenção, processamento e memória estão mais focados em eventos negativos do que positivos.

Então, para uma mãe e seu filho esta pode ser uma grande barreira afetiva, visto que os indivíduos podem ser afetados por fenômenos internos, como raiva e ansiedade. Logo, com mais afetos negativos, maiores as chances de as relações serem prejudicadas, assim como o afeto entre mãe e filho.

Resultados qualitativos 
Após a realização das entrevistas e transcrição das mesmas, foram construídas categorias a partir dos diálogos e falas das participantes. Esta etapa foi realizada para complementar os dados quantitativos e compreender quais situações são vivenciadas pelas mulheres avaliadas.

A seguir serão apresentadas as categorias construídas a partir das entrevistas, no qual os dados qualitativos serão triangulados com os dados quantitativos. Logo, as categorias de violência e depressão e ansiedade podem ser relacionadas com os escores altos de afetos negativos e escores baixos de afetos positivos. Como este artigo é baseado nos estudos de KristinNeff, como escrito anteriormente, a categoria de pensamentos autocríticos e culpa estão diretamente relacionados com os escores de autocompaixão. Conforme Souza e Hutz (2016), quanto mais elevada a autocompaixão, menor será o autocriticismo e sentimentos negativos.

\section{Violência}

Entre muitas falas, foi possível observar a violência como sendo um fator importante apresentado pelas entrevistadas. Dentro desta categoria foi encontrado violências do tipo físico, psicológico e sexual, cometidos tanto por membros da família, parceiros e pessoas desconhecidas da entrevistada. De acordo com Zancan et al. (2013, p.68),“o cotidiano dessas mulheres envolve conflitos constantes de submissão, menosprezo, solidão e humilhação, expostos pela violência física, sexual e psicológica, no qual a expressam como uma convivência encoberta pelo dominado, por ausência de cuidados e afeto".

O Ministério da Saúde caracteriza como Violência Intrafamiliar quando um indivíduo se encontra em uma relação de poder sobre outra pessoa, no qual o uso de força física ou algum tipo de arma é utilizado na intenção de provocar lesões e causar danos na outra pessoa (BRASIL, 2001). Dentre as entrevistadas, quatro delas relataram terem sofrido violência física, tanto por parceiros como por familiares (Tabela 2).

De acordo com Zancan et al. (2013), a violência psicológica geralmente evolui para uma violência física, o que pôde influenciar o desempenho da participante P5 
na aplicação das escalas, no qual apresentou as seguintes falas: "Fiquei presa dentro de casa, se eu saísse ele me batia, nem na rua não podia nem levar o lixo na rua, nada" e "primeiro, quando me conheceu me disse como meus filhos eram educados, tu é uma mãe boa. Depois ele dizia, 'tu não é mulher pra nada', sabe?’. Neste caso, P5 relata ter sofrido violência física e psicológica, e também se enquadra no percentil 5 de afetos positivos e 15 do nível de autocompaixão (Tabela 1). Ou seja, possui escore de afetos positivos apenas $5 \%$ e $15 \%$ maiores do que a amostra padronizada.

Conforme Silva et al. (2007), os diferentes tipos de violência se desenvolvem de forma interligada, ou seja, elas se misturam de diferentes formas. Logo, a violência física e psicológica diferenciam, pois a violência física envolve agressão corporal à vítima. Entretanto, a violência psicológica tem como forma de agressão a utilização de palavras, gestos e olhares direcionados à vítima, sem ter contato físico. Conforme o Ministério da Saúde (2001 apud SILVA et al, 2007), toda ação ou omissão que tem como intenção causar algum dano à autoestima, à identidade ou ao desenvolvimento da pessoa, é caracterizado como violência psicológica.

Na Tabela 2 é possível ver que três participantes, P3, P5 e P7, relataram já terem sofrido violência psicológica. Elas também se enquadram em percentis de autocompaixão baixos 5, 15 e 25, respectivamente. Estas participantes também alcançaram o percentil 5 de afetos positivos, o que indica que as mesmas possuem um escore de afetos positivos maior do que apenas 5\% das participantes da amostra padronizada de Hutzet al. (2014). Em sua entrevista, P3 conta que: "Indignação.... Eu sempre lembro do meu marido né? Ele faz sempre questão de mostrar que eu não valho nada, que o que eu faço tá sempre errado". A partir do relato de P3, conseguese identificar uma relação direta com a vivência de maiores afetos negativos e menores afetos positivos, o que pode justificar também um baixo escore em autocompaixão, pois sendo criticada como ela relata, pode aumentar seu autocriticismo, diminuindo a autocompaixão (SOUZA e HUTZ, 2016).

Conforme Zancan et al. (2013, p. 68), "a violência sexual, também presente no cotidiano das mulheres, é caracterizada como um ataque em que o agressor, sem o consentimento da mulher, obriga-a a manter relações sexuais pela força ou por ameaça”. Durante as entrevistas apenas duas mulheres relataram terem sofrido 
violência sexual. P6 relata ter sofrido assédio sexual dos 9 aos 13 anos. De acordo com sua fala, P6 conta que fez terapia e hoje consegue lidar com o que ocorreu, entretanto afetou a forma como ela se preocupa com seus filhos: "Eu sofri assédio sexual dos 9 aos 13 né. E então assim, é bem difícil eu confiar em outras pessoas, deixar os meus filhos dormirem em casa de amigos". Já a P8 conta que: "Dai a última coisa que aconteceu aonde eu morava lá, foi que entrou um cara e abusou de mim”. Já P8 que sofreu abuso sexual já na vida adulta, não contou se fez ou não acompanhamento psicológico, porém conta que este fato a atormenta até hoje, lhe causando muito medo.

Estas participantes tiveram escores de afetos positivos e negativos diferentes, $\mathrm{P} 6$ teve maior escore de afetos positivos e menor de afetos negativos. Já a P8 teve o inverso, menor escore de afetos positivos e maior de afetos negativos. No qual pode ter influenciado no percentil de autocompaixão em que as mesmas se enquadram, sendo 45 e 30 , respectivamente.

Depressão e ansiedade

De acordo com a Organização Mundial da Saúde (2001) e a American Psychiatric Association (2002), os profissionais de saúde relatam que a depressão é um dos problemas de saúde mais comuns, no qual entre as características e sintomas se encontram o humor deprimido, visto que o humor pode acarretar na diminuição de outros comportamentos (como por exemplo, andar, falar, ter relações sociais) e o aumento de outros comportamentos, como por exemplo fuga-esquiva. Isto ocorre como forma de evitar o contato com o estímulo aversivo e podendo ser queixa de labilidade emocional, irritabilidade, lentidão para responder aos estímulos diários, pedidos de ajuda e ideias suicidas.

Conforme Allen et al. (1995), a ansiedade é um sentimento desagradável de medo excessivo, apreensão, caracterizado por tensão ou desconforto que se desenvolve por meio da antecipação do perigo, de algo desconhecido ou estranho.

Todas estas características que remetem à depressão e ansiedade foram consideradas para a categorização das falas, por exemplo, usar falas como na fala de P2: "Dor no peito, eu tenho muita dor no peito... É isso quando eu me incomodo 
e quando eu to ansiosa" e na fala de $\mathrm{P} 1$ : "Porque às vezes dá vontade de não continuar". Entre dez entrevistas, sete participantes apresentaram falas que remetem a depressão e ansiedade. Dentre estas sete mulheres, cinco delas relataram já terem sofrido quadros de depressão, como no caso de P2, P3, P5, P7 e P9, sendo que apenas a P2 não teve alguma fala sobre ter sofrido algum tipo de violência. Já as participantes P1 e P8 apresentaram falas que remetem à caracterização de depressão e ansiedade, sendo que estas duas mulheres sofreram violência física e violência sexual, respectivamente.

É possível verificar que na Tabela 2, as participantes P4, P6 e P10 não apresentaram falas sobre depressão e ansiedade. E as mesmas são as que possuem os maiores escores de autocompaixão (Tabela 1). Conforme Simões (2012, p.14) "num estudo exploratório levado a cabo por MacBeth \& Gumley (2012), foi possível verificar que a compaixão e auto-compaixão se encontram negativamente associadas à sintomatologia psicopatológica, nomeadamente, depressão, ansiedade e stress".

Logo, através desta citação é possível sustentar os resultados encontrados entre a relação de autocompaixão nas participantes que não apresentaram falas sobre depressão e ansiedade. Assim, pode-se ver a importância de olhar mais aspectos qualitativos sobre o sujeito e não apenas os escores resultantes da aplicação das escalas, para conseguir tentar entender a motivação que está por detrás dos resultados.

Segundo Brito (2009), existe um sentimento de culpa gerado no processo depressivo no qual a mulher sente culpa por esses sentimentos, ou pelos afetos negativos sofridos. Ainda Brito (2009), coloca que no papel de mãe o sentimento de incapacidade de ter uma relação de afeto saudável com o filho, como relatado por muitas participantes da pesquisa. Como no caso de P3:

E é difícil não passar isso pro meu filho, né? Não transparecer, eu sou uma pessoa, eu tenho depressão, ai quando eu to medicada, que eu infelizmente não posso nem comprar um remédio, quando eu to medicada eu to um pouco melhor... Ele só me vê pra baixo, o tempo todo, é muito difícil eu tá rindo, é muito difícil eu tá. Ai eu fico mais triste ainda, porque eu vejo que ele vê isso 
Com relação à incapacidade, é possível compreender como isto pode trazer sofrimento para estas mulheres, como ainda relata P3: "Incapacidade, é... Como que eu vou especificar as palavras... Sou fraca! Parece assim que eu não vou vencer as coisas, não vou conseguir... E... Meu, tipo, incapaz mesmo, incapaz de fazer".

Conforme Castillo et al. (2000), a ansiedade é caracterizada por preocupações excessivas acerca das circunstâncias da vida, no qual surgem também sintomas fisiológicos, podendo durar algumas semanas ou a maior parte de seus dias. Ainda conforme Souza e Hutz (2016) é apontado que quando a autocompaixão se encontra elevada em um indivíduo, existe uma menor associação de depressão, ansiedade e estresse. Desta forma, assim como na depressão, estes sintomas da ansiedade podem acabar interferindo na relação de afeto entre mãe e filho, podendo refletir no desenvolvimento da criança e adolescente.

Autocrítica e culpa

Conforme Gilbert et al. (2004), autocriticismo se dá quando o indivíduo persegue e acusa a si mesmo, apontando seus próprios erros, ou seja, é estabelecida uma relação eu-eu no qual o auto ataque interno ocorre de forma constante. Consegue-se compreender a relação do autocriticismo pela fala da participante P7: "Porque eu sou feia, porque eu não sou capaz, porque eu não sou boa mãe, sabe? [...] A primeira coisa que eu falo pra mim mesma, esses dias eu me dei conta. A frase que eu falo pra mim todo dia de manhã é que eu não consigo, entendeu?".

O autocriticismo também está relacionado ao sentimento de culpa, visto que o indivíduo tem dificuldade para aceitar seus erros e dificuldades. É possível verificar a relação com a culpa a partir da fala de P2: "ai, eu às vezes me culpo assim (sobre o desenvolvimento escolar do filho), por...por sei lá, às vezes eu penso que é culpa minha que ele tem esse problema, que ele tá com dificuldade. Eu sofro bastante quanto a isso... É muito doloroso".

De acordo com Gilbert (2007), a culpa e o remorso evoluíram de um sistema de evitação "causar-mal” no contexto de cuidado. Ainda como Gilbert (2007), “a capacidade de processar e tolerar a culpa (tristeza, pesar e o remorso pelos prejuízos causados) e se engajar em ações reparadoras são importantes para nossos 
relacionamentos de afiliação".

Desta forma, o autocriticismo e a culpa foram encontrados dentro do diálogo de todas as participantes, no qual as mesmas obtiveram escores diferentes entre as escalas de autocompaixão, afetos positivos e afetos negativos.

Neste sentido, estudos recentes apontam para que uma pessoa que não experiencie compaixão ou que experiencie excessiva negatividade por parte do cuidador, durante o desenvolvimento do sistema de conforto/segurança (i.e. infância e adolescência), tende a apresentar níveis elevados de autocriticismo, de vergonha e de culpa na idade adulta, como resultado direto dessas experiências (GILBERT, 2009; GILBERT et al.2004 apud GILBERT, 2014, p.6).

Conforme Neff (2003), a autocompaixão está relacionada de forma negativa com o auto-criticismo, à depressão, ansiedade, ruminação, supressão de pensamento, ao perfeccionismo neurótico e à afetividade negativa no geral. A partir das falas apresentadas, pode-se compreender mais a relação entre os percentis de autocompaixão e afetos negativos apresentados nos dados quantitativos.

A partir destas categorizações foi construído uma tabela para demonstrar de forma visível em quais categorias cada participante foi associada.

Tabela 2: categorização de aspectos presentes nas falas das participantes

\begin{tabular}{cccccc}
\hline Participante & $\begin{array}{c}\text { Violência } \\
\text { física }\end{array}$ & $\begin{array}{c}\text { Violência } \\
\text { Psicológica }\end{array}$ & $\begin{array}{c}\text { Violência } \\
\text { Sexual }\end{array}$ & $\begin{array}{c}\text { Depressão e } \\
\text { ansiedade }\end{array}$ & $\begin{array}{c}\text { Autocriticismo } \\
\text { e culpa }\end{array}$ \\
\hline P1 & Sim & & Sim & Sim \\
\hline P2 & & Sim & Sim \\
\hline P3 & & Sim & Sim \\
\hline P4 & Sim & & Sim & Sim \\
\hline P5 & Sim & Sim & & Sim \\
\hline P6 & Sim & & & Sim & Sim \\
\hline P7 & & Sim & Sim & Sim & Sim \\
\hline P8 & & & Sim & Sim \\
\hline P9 & Sim & &
\end{tabular}


$\mathrm{P} 10$ Sim

Fonte: Primária (2019).

Considerações finais

Esta pesquisa teve como seu principal objetivo investigar o grau de autocompaixão e de afetos negativos/positivos em mães de filhos atendidos em um ambulatório psicológico. A partir dos resultados foi encontrada uma relação entre escores altos de afetos negativos e escores baixos de autocompaixão, sendo que os escores de afetos positivos variaram entre as participantes. Além dos dados quantitativos, foram construídas categorias identificadas em comum entre os diálogos das participantes, sendo que todas categorias podem ter influenciado os escores de afetos negativos e autocompaixão obtidos para cada participante.

Com base nos dados obtidos, foi possível compreender como as dificuldades de ser mãe não só estão relacionadas com a compaixão pelos filhos, mas como isso implica na autocompaixão delas. Com a demonstração dos altos afetos negativos, foi possível verificar a necessidade de um espaço de fala para estas mulheres e como o auxílio psicológico pode contribuir tanto para uma saúde mental destas mães, como influenciar a relação delas com os filhos. Muitas mães relataram dificuldades com redes de apoio, que também dificulta a capacidade de dar todo suporte necessário para si e para o outro.

A partir das categorizações das falas, entende-se que a maioria das participantes sofreu algum tipo de violência. Sendo este um dado muito importante e sério, visto que grande parte destas violências foram cometidas por pessoas próximas destas mulheres. A violência também pode estar relacionada com a saúde mental das participantes, bem como a visão e percepção de si mesmas. Desta forma, acarretando no baixo escore de autocompaixão e afetos positivos, e também aumentando os escores de afetos negativos.

Logo, compreende-se como um trabalho com a autocompaixão poderia ter um impacto positivo na vida das participantes, bem como dos outros que convivem com elas. Sendo uma forma de reconhecer e obter uma visão mais ampla sobre o sofrimento do outro, e no caso da autocompaixão, sobre seu próprio sofrimento. A importância de se trabalhar com a família no processo terapêutico de uma criança 
ou adolescente pode gerar um desenvolvimento mais saudável deles e também em outros familiares.

Outros estudos sobre autocompaixão, afetos positivos e negativos poderiam vir a ocorrer, devido a gama de informações coletadas, bem como os dados qualitativos. Também é importante desenvolver outros estudos sobre maternidade e os impactos na criação de filhos.

Consequentemente, este artigo poderá abrir caminhos para novos estudos voltados para a relação entre autocompaixão, maternidade, maternagem e afetos positivos e negativos. Esta pesquisa também contribuiu para as participantes terem a oportunidade de um espaço de fala sobre seu sofrimento, sendo a escuta terapêutico para muitas delas.

Esta pesquisa apresenta algumas limitações, visto que provavelmente existem outros aspectos qualitativos que podem ter influenciado no resultado obtido pelos escores e que não foram contemplados nesta pesquisa, como aspectos socioeconômicos e demográficos.

Devido ao tamanho da amostra desta pesquisa, não podemos dizer que os resultados apresentados definem o comportamento da população, ou seja, de todas as mães que possuem filhos que fazem atendimento psicológico, visto que estatisticamente não seria válido. Entretanto, os resultados apresentados foram valiosos a fim de compreender mais a fundo a amostra pesquisada, e assim verificar o impacto que a violência, depressão e ansiedade, autocrítica e culpa gera nos escores de afetos positivos, negativos e autocompaixão apresentados para cada participante.

Referências

ALLEN, AJ et al. Current knowledge of medications for the treatment of childhood anxiety disorders. J Am Acad Child Adolesc Psychiatry. v. 34, 1995. DOI: 10.1097 / $00004583-$ 199508000-00007.

AMERICAN PSYCHIATRIC ASSOCIATION. (2002). Diagnostic and statistical manual of mental disorders - IV-TR, Fourth Edition. Washington, DC (Manual Diagnóstico e Estatístico de Transtornos Mentais). (D. Batista, Trad.). Porto Alegre: Artes Médicas Sul. 
APÓSTOLO, João et al. Depressão, ansiedade e stress em utentes de cuidados de saúde primários. Revista referência, n.8, 2008. Disponível em: <https://webcache.googleusercontent.com/search?q=cache:ulO4TLkh7iUJ:https://web.ese nfc.pt/v02/pa/conteudos/downloadArtigo.php\%3Fid_ficheiro\%3D246\%26codigo\%3D+\&cd $=3 \& \mathrm{hl}=\mathrm{pt}-\mathrm{BR} \& \mathrm{ct}=\mathrm{clnk} \& \mathrm{gl}=\mathrm{br}>$. Acesso em: 06 nov. 2019 .

BONI, Valdete; QUARESMA, Sílvia Jurema. Aprendendo a entrevistar: como fazer entrevistas em Ciências Sociais. 2005. DOI: https://doi.org/10.5007/\%25x. Disponível em: $<$ https://periodicos.ufsc.br/index.php/emtese/article/view/18027/16976>. Acesso em: 31 mar. 2019.

BRASIL. Ministério da Saúde. O que é a violência contra a mulher?. 2001. Disponível em $<$ http://portal.saude.gov.br/saude/visualizar_texto.cfm?idtxt=33903>. Acesso em: 04 out. 2019 .

BRASIL. Ministério da Saúde. Secretaria de Políticas de Saúde. Violência intrafamiliar: orientações para a prática em serviço. Brasília: Ministério da Saúde, 2001. (Caderno de Atenção Básica, 8)

BRITO, Isabel. A saúde mental na gravidez e primeira infância. Rev. Port. Clín. Geral, 2009. DOI: http://dx.doi.org/10.32385/rpmgf.v25i5.10678. Disponível em: <http://www.rpmgf.pt/ojs/index.php/rpmgf/article/view/10678/10414>. Acesso em: 01 nov. 2019.

CASTILLO, Ana Regina GL et al.. Transtornos de ansiedade. Rev. Bras. Psiquiatr., São Paulo, v. 22, supl. 2, p. 20-23,Dec. 2000. DOI: https://doi.org/10.1590/S151644462000000600006. Disponível em: <http://www.scielo.br/pdf/rbp/v22s2/3791.pdf>. Acesso em: 06 nov.2019.

CAVALCANTE, Ricardo Bezerra; CALIXTO, Pedro; PINHEIRO, Marta Macedo Kerr. Análise de Conteúdo: considerações gerais, relações com a pergunta de pesquisa, possibilidades e limitações do método. Informação e Sociedade: estudos, v.24, n.1, p. 1318 , 2014.

Disponível em:<https://www.researchgate.net/profile/Ricaro_Cavalcante/publication/329399124_Ana lise_de_Conteudo_consideracoes_gerais_relacoes_com_a_pergunta_de_pesquisa_as_possi bilidades_e_limitacoes_do_metodo/links/5c06757492851c6ca1fd4eec/Analise-deConteudo-consideracoes-gerais-relacoes-com-a-pergunta-de-pesquisa-as-possibilidades-elimitacoes-do-metodo.pdf>. Acesso em: 1 nov. 2019.

DIENER, E.;OISHI, S.; LUCAS, R. E. Subjective Well-Being. The Science of Happiness and Life Satisfaction. In: C. R. Snyder, \& S. J. Lopez (Eds.), The Handbook of Positive Psychology. 2nd ed., p. 187-194, 2009. New York: Oxford University Press. DOI: https://doi.org/10.1093/oxfordhb/9780195187243.013.0017. Disponível em:< https://greatergood.berkeley.edu/images/application uploads/Diener-Subjective WellBeing.pdf >. Acesso em: 6 nov. 2019.

GERHARDT, Tatiana Engel; SILVEIRA, Denise Tolfo. Métodos de pesquisa. Porto Alegre: Editora da UFRGS, 2009. DOI: http://hdl.handle.net/10183/52806. Disponível em: < https://lume.ufrgs.br/handle/10183/52806 >. Acesso em: 6 nov. 2019. 
GILBERT, P.et al. Criticizing and reassuring one self: An exploration of forms style and reasons in females tudents. British Journal of Clinical Psychology, 43, 31-50, 2004. DOI: https://doi.org/10.1348/014466504772812959. Disponível em: < https://onlinelibrary.wiley.com/doi/10.1348/014466504772812959>. Acesso em: 1 nov. 2019.

GILBERT, P. The evolution of shame as a marker for relationship security. In J. L. Tracy, R. W. Robins\& J. P. Tangney (Eds.), The self-conscious emotions: Theory and research. p. 283-309, 2007. New York, NY: Guilford.

GILBERT, Paul; TIRCH, Dennis D. Memória emocional, mindfulness e compaixão. Clinical Handbook of Mindfulness, capítulo 6, p. 99-110, 2009. DOI: https://doi.org/10.1007/978-0-387-09593-6_7.

GILBERT, Paul. Uma introdução à terapia focada na compaixão na Terapia Cognitivocomportamental. International Journal of Cognitive Therapy, 3(2), p. 97-112, 2010. DOI: https://doi.org/10.1521/ijct.2010.3.2.97. Disponível em: https://guilfordjournals.com/doi/pdf/10.1521/ijct.2010.3.2.97 >. Acesso em: 6 nov. 2019.

GILBERT, Paul. As origens e a natureza da terapia focada na compaixão. British Journal of Clinical Psychology, 2014. DOI: https://doi.org/10.1111/bjc.12043. Disponível em: < https://www.academia.edu/32802664/Tradu\%C3\%A7\%C3\%A3o_As_origens_e a naturez a_da_terapia_focada_na_compaix\%C3\%A3o_Gilbert_2014_>. Acesso em: 6 nov. 2019.

GODOY, Arlida Schmidt. Introdução à pesquisa qualitativa e suas possibilidades. Rev.adm.empres., São Paulo, v. 35, n. 2, p. 57-63, abr. 1995. https://doi.org/10.1590/S003475901995000200008. Disponível em:<http://www.scielo.br/pdf/rae/v35n2/a08v35n2.pdf $>$. Acesso em: 31 mar. 2019.

GÜNTHER, Hartmut. Pesquisa Qualitativa Versus Pesquisa Quantitativa: Esta É a Questão? Psicologia: Teoria e Pesquisa, mai-ago 2006, vol. 22 n. 2, p. 201-210. DOI: https://doi.org/10.1590/s0102-37722006000200010. $\quad$ Disponível em:< https://www.scielo.br/pdf/ptp/v22n2/a10v22n2.pdf > . Acesso em: 29 out.2019.

HUTZ, Claudio Simon et al. Avaliação em psicologia positiva. 2014.

HUTZ, Claudio Simon. Avaliação em psicologia positiva - Técnicas e medidas. s. l. Editora Hogrefe $1^{\text {a }}$ ed. 2016.

JEFFRIES, Sherryl M; KONNERT, Candace. Regret and psychologic well-being among voluntarily and involuntarily childless women and mother. 2002. DOI: https://doi.org/10.2190/j08n-vbvg-6pxm-0ttn. Disponível em: <https://pubmed.ncbi.nlm.nih.gov/12054274/>. Acesso em: 1 nov. 2019. 
NEFF, Kristin. Self-Compassion: An Alternative Conceptualization of a Healthy Attitude Toward Oneself. Psychology Press, 2003. DOI: https://doi.org/10.1080/15298860309032. Disponível em: < https://self-compassion.org/wpcontent/uploads/publications/SCtheoryarticle.pdf>. Acesso em: 6 nov. 2019.

NEFF, Kristin. Autocompaixão: pare de se torturar e deixe a insegurança para trás. 1. Ed. Teresópolis, RJ: Lúcida Letra, 2017.

ORGANIZAÇÃO MUNDIAL DA SAÚDE. Relatório sobre a saúde no mundo: nova concepção, nova esperança. 2001. Disponível em: $<$ https://webcache.googleusercontent.com/search?q=cache:F267q174uPQJ:https://www.w ho.int/whr/2001/en/whr01_djmessage_po.pdf+\&cd=1\&hl=pt-BR\&ct=clnk\&gl=br>. Acesso em 01 nov. 2019.

SANCHEZ, Marisa Marantes. A terapia cognitivo-comportamental na atenção Mãe-Bebê: uma nova proposta. IN: RUDNICKI, Tânia; SANCHEZ, Marisa Marantes. Psicologia da saúde: a prática da terapia cognitivo-comportamental em hospital geral. Synopsys Editora, 2014. cap. 5, p. 102-120.

SILVA, Luciane Lemos da; et al. Violência silenciosa: violência psicológica como condição da violência física doméstica. Interface - Comunic., Saúde, Educ., 11(21), 93-103, 2007. DOI: $\quad$ https://doi.org/10.1590/S1414-32832007000100009. Disponível em: < https://www.scielo.br/pdf/icse/v11n21/v11n21a09.pdf >. Acesso em: 03 out. 019.

SIMÕES, Diana Silva Castro. Medo da compaixão: estudo das propriedades psicométricas da Fears of Compassion Scales (FCS) e da sua relação com medidas de vergonha, compaixão e psicopatologia. Universidade de Coimbra, 2012. http://hdl.handle.net/10316/23280. Disponível em: <https://estudogeral.sib.uc.pt/bitstream/10316/23280/1/diana.simoes.pdf>. Acesso em: 25 out. 2019.

SOUZA, Luciana Karine de; HUTZ, Claudio Simon. A autocompaixão em mulheres e relações com autoestima, autoeficácia e aspectos sociodemográficos. Psico (Porto Alegre), Porto Alegre, v. 47, n. 2, p. 89-98,2016. DOI: https://doi.org/10.15448/19808623.2016.2.21185. Disponível em: < http://pepsic.bvsalud.org/pdf/psico/v47n2/01.pdf $>$. Acesso em: 10 out. 2019.

WOYCIEKOSKI, Carla; STENERT, Fernanda; HUTZ, Claudio Simon. Determinantes do Bem-Estar Subjetivo. Psico, ISSN 0103-5371, vol. 43, $\mathrm{n}^{\circ}$. 3, 2012. Disponível em: $<$ https://dialnet.unirioja.es/servlet/articulo?codigo $=5631411>$. Acesso em: 06 nov. 2019.

WOYCIEKOSKI, Carla; NATIVIDADE, Jean Carlos; HUTZ, Carlos Simon. As Contribuições da Personalidade e dos Eventos de Vida para o Bem-Estar Subjetivo. Psicologia: Teoria e Pesquisa, out-dez 2014, vol. 30 n. 4, pp. 401-409. DOI: 10.1590/S010237722014000400005. Disponível em: < https://www.scielo.br/pdf/ptp/v30n4/v30n4a05.pdf >. Acesso em: 06 nov. 2019. 
ZANCAN, Natália; WASSERMANN, Virginia; LIMA, Gabriela Quadros de. A violência doméstica a partir do discurso de mulheres agredidas. Pensando fam., Porto Alegre,v. 17, n. 1 , p. 63-76, jul. $2013 . \quad$ Disponível em: $<$ http://pepsic.bvsalud.org/pdf/penf/v17n1/v17n1a07.pdf >. Acesso em: 06 nov. 2019.

Recebido em janeiro de 2021. Aprovado em março de 2021. 